\title{
Direct electrochemical production of pseudo-binary Ti-Fe alloys from mixtures of synthetic rutile and iron(III) oxide
}

\author{
Simon J. Graham ${ }^{1, \star}$, Lyndsey L. Benson ${ }^{2}$, and Martin Jackson ${ }^{1}$ \\ 'Department of Materials Science and Engineering, The University of Sheffield, Sir Robert Hadfield Building, Mappin Street, \\ Sheffield S1 3JD, UK \\ ${ }^{2}$ Metalysis Materials Discovery Centre, Units 4A \& 4B, Brindley Way, Catcliffe, Rotherham S60 5FS, UK
}

Received: 7 July 2020

Accepted: 9 August 2020

Published online:

31 August 2020

(C) The Author(s) 2020

\begin{abstract}
Combining the FFC-Cambridge process with field-assisted sintering technology (FAST) allows for the realisation of an alternative, entirely solid-state, production route for a wide range of metals and alloys. For titanium, this could provide a route to produce alloys at a lower cost compared to the conventional Krollbased route. Use of synthetic rutile instead of high purity $\mathrm{TiO}_{2}$ offers further potential cost savings, with previous studies reporting on the reduction of this feedstock via the FFC-Cambridge process. In this study, mixtures of synthetic rutile and iron oxide $\left(\mathrm{Fe}_{2} \mathrm{O}_{3}\right)$ powders were co-reduced using the FFC-Cambridge process, directly producing titanium alloy powders. The powders were subsequently consolidated using FAST to generate homogeneous, pseudo-binary $\mathrm{Ti}-\mathrm{Fe}$ alloys containing up to $9 \mathrm{wt}$.\% Fe. The oxide mixture, reduced powders and bulk alloys were fully characterised to determine the microstructure and chemistry evolution during processing. Increasing Fe content led to greater $\beta$ phase stabilisation but no TiFe intermetallic phase was observed in any of the consolidated alloys. Microhardness testing was performed for preliminary assessment of mechanical properties, with values between 330-400 Hv. Maximum hardness was measured in the alloy containing $5.15 \mathrm{wt} . \% \mathrm{Fe}$, thought due to the strengthening effect of fine $\alpha$ phase precipitation within the $\beta$ grains. At higher Fe contents, there was sufficient $\beta$ stabilisation to prevent $\alpha$ phase transformation on cooling, leading to a reduction in hardness despite a general increase from solid solution strengthening.
\end{abstract}

Handling Editor: Sophie Primig.

Address correspondence to E-mail: sjgraham1@sheffield.ac.uk 


\section{Introduction}

Titanium and its alloys have impressive properties, including high strength to weight ratio, corrosion resistance and biocompatibility, making them desirable for use in a wide variety of applications. The costs associated with current production prevent widespread use however, despite relative abundance of the ores. Therefore, there are many circumstances, for example in the automotive industry, where it would be preferable to use a Ti alloy, but an inferior material is used due to lower cost. Significantly reducing costs requires the realisation of an alternative production route, which is becoming increasingly plausible with novel extraction and processing techniques. Combining the FFC-Cambridge process with field-assisted sintering technology (FAST) offers an alternative, entirely solid-state processing route (Fig. 1).

\section{Ti extraction via the FFC-Cambridge process}

The FFC-Cambridge process was first reported in 2000 by researchers Fray, Farthing and Chen as an electrolytic method for extracting Ti metal from its oxide [1]. The process has since been shown to be capable of reducing many different metal oxides, including those of tantalum, chromium and cerium [2-4]. Mixed-metal oxides can also be reduced simultaneously, allowing for the direct production of alloys, as well as more novel materials like high-entropy alloys and those derived from lunar regolith simulant material [5-9].

The process uses an electrochemical cell, consisting of a metal oxide cathode and a graphite anode, submerged in a molten salt electrolyte, usually $\mathrm{CaCl}_{2}$. Applying sufficient voltage causes ionisation of the oxygen at the cathode, which is then transported through the electrolyte to react with the graphite carbon anode. This overall oxygen transfer results in deoxidised metal(s) and generation of $\mathrm{CO}$ and $\mathrm{CO}_{2}$ gas (Eqs. 1-3).

$$
\begin{aligned}
& \mathrm{M}_{x} \mathrm{O}_{y}+2 y e^{-} \rightarrow x \mathrm{M}+y \mathrm{O}^{2-} \\
& \mathrm{C}+2 \mathrm{O}^{2-} \rightarrow \mathrm{CO}_{2}+4 e^{-} \\
& \mathrm{C}+\mathrm{O}^{2-} \rightarrow \mathrm{CO}+2 e^{-}
\end{aligned}
$$

This is a simplified description of the process however, and various studies have been published on understanding the process in more detail. Partial reductions have been used to study the reduction pathway of metal oxides, revealing that they reduce via intermediate suboxides and $\mathrm{Ca}$ compounds [10-14]. $\mathrm{Ca}^{2+}$ ions are incorporated from the electrolyte and facilitate the transfer of $\mathrm{O}^{2-}$ ions to the anode. Additions of $\mathrm{CaO}$ were found to accelerate the rate of electro-deoxidation of $\mathrm{TiO}_{2}$ by providing an initial source of $\mathrm{O}^{2-}$ ions. This sustains the ionic current, preventing $\mathrm{Cl}_{2}$ formation and increasing current efficiency [15]. There has been some debate on the nature of $\mathrm{O}^{2-}$ ion transport through the electrolyte, with a recent study suggesting that when low amounts of $\mathrm{CaO}$ are present, transport occurs by diffusion and not migration [16].

Meanwhile, UK technology company Metalysis has been improving and scaling up the FFC-Cambridge process to create alloy powders on a commercial scale, designing facilities with the capability to produce tens to hundreds of tonnes of alloys per annum. Improvements to the process include the ability to directly reduce oxides in powder form, without the need for compaction into preform pellets [17].

The FFC-Cambridge process has gained particular interest for producing $\mathrm{Ti}$ and its alloys, due to the potential advantages it has over conventional Krollbased extraction. These include being a single-step process, using oxide directly rather than $\mathrm{TiCl}_{4}$ and having lower projected costs. Current titanium alloy powder production methods involve further processing of billets, such as atomisation or hydridedehydride, which further increases their price.

Figure 1 Proposed alternative Ti extraction and processing route used in this study.

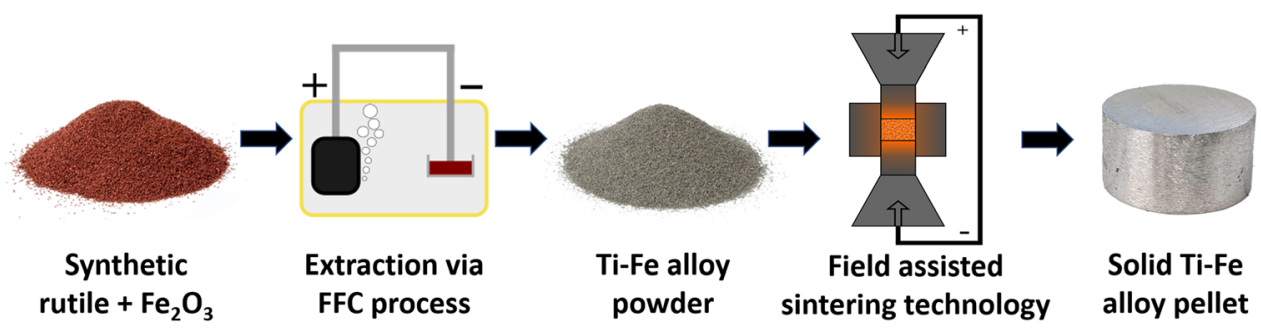


Therefore, the ability to directly produce alloy powders makes the FFC-Cambridge process appealing for a range of downstream powder metallurgy manufacturing routes.

To assess projected costs, a life cycle analysis study estimated that Ti production via the FFC-Cambridge process could reduce 'gross energy requirements' and 'global warming potential' by $10-15 \%$ compared to conventional Kroll production; with further reductions of 30-35\% achievable using lower $\mathrm{TiO}_{2}$ purity feedstock [18]. Developments to the process have been investigated to make it even more attractive for Ti extraction, including use of more sustainable feedstocks, improving current efficiencies, use of inert anodes which prevent $\mathrm{CO}_{2}$ generation and production of near-net shape components from shaped oxide precursors [15, 19-21]. A recent study on the use of shaped oxide via the 'Near-net-shape Electrochemical Metallisation (NEM) process' attempted to quantify the environmental impacts of components produced using this method, compared to electron beam melting of Kroll derived, gas atomised powders. It found that the NEM process dramatically reduced the overall environmental impact by about $68 \%$ in comparison [22]. Overall, the continued research and improvement of Ti extraction via the FFC-Cambridge process, along with supporting evidence of the potential advantages, demonstrates the potential for further exploitation of this technology in the future.

Until recently, most research has used pigment grade rutile $\left(\mathrm{TiO}_{2}\right)$ to produce $\mathrm{Ti}$ via the FFC-Cambridge process; but significant cost reduction can be achieved using lower purity precursor materials instead $[22,23]$. One example is synthetic rutile (SR), which contains around $90-95 \% \mathrm{TiO}_{2}$, and is usually further processed into $\mathrm{TiCl}_{4}$ for use in conventional Kroll extraction [24]. It is produced from ilmenite ore $\left(\mathrm{FeTiO}_{3}\right)$ via an $\mathrm{Fe}$ removal process, such as the Becher process [25]. Some impurity elements such as $\mathrm{Fe}, \mathrm{Al}$ and $\mathrm{Mn}$ remain, with their relative amounts depending on the ilmenite source and processing conditions. Previous studies have directly reduced this material using the FFC-Cambridge process, producing a Ti alloy powder naturally containing these impurities as alloying elements [26]. The reduction pathway was also fully characterised and was found to be consistent with that of pure $\mathrm{TiO}_{2}$ but with variations due to reductions of the other remnant elements. Overall, further investigation of SR as a feedstock in this production route is attractive for cost reduction while benefitting from already present alloying elements.

\section{Field-assisted sintering technology (FAST)}

FAST (also referred to as spark plasma sintering) is a consolidation technique suitable for many different powdered materials, including $\mathrm{Ti}$ powders [27]. It combines uniaxial pressure and joule heating, from pulsed direct current, to achieve high heating rates and rapid sintering. Consolidation occurs in the solid-state, preventing any melt-related defects which can arise during conventional processing. Segregation defects have limited the use of some alloying elements in Ti, including $\mathrm{Fe}$, and so FAST can be used for new alloy development using these elements. Although FAST is currently only able to produce billets up to $300 \mathrm{~mm}$ in diameter, it can be combined with a subsequent forging step to create near-net shape components, developed as the FAST-forge process [28]. $\mathrm{Ti}$ alloy powder derived from SR reduction in the FFC-Cambridge process has previously been consolidated using FAST, generating a homogeneous $\alpha+\beta$ microstructure with compressive mechanical properties comparable to Ti-6Al-4V processed under the same conditions [29].

\section{Fe additions in Ti alloys}

Fe is the most effective Ti $\beta$ phase stabiliser by mass, thus less Fe is required to achieve the same level of $\beta$ stabilisation as other elements. Fe is also considerably cheaper than $\mathrm{Ti}$ and commonly used $\beta$ stabilisers such as $\mathrm{V}$ and Mo, although it is not used in many commercial Ti alloys. Restricted use of Fe is generally due to processing issues associated with the melting process which can affect the quality of the resulting alloys. Segregation of Fe during vacuum arc remelting can lead to localised regions of high $\beta$ stability known as $\beta$ flecks, which cause worse than expected mechanical performance [30]. Solid-state alloying using blended elemental powder metallurgy has been shown to avoid these issues. Ti alloys up to 7 wt.\% Fe have been produced by press and sintering of blended elemental and alloy powders to produce homogeneous microstructures with no trace of intermetallic phases [31-33].

Most metastable $\beta$ alloys, such as Ti-3Al-8V-6Cr$4 \mathrm{Mo}-4 \mathrm{Zr}$ (Beta C) and Ti-15V-3Cr-3Al-3Sn, contain 
lots of costly alloying elements. An addition of only $3.5 \mathrm{wt} \% \mathrm{Fe}$ is required to retain $100 \% \beta$ phase after quenching to room temperature, therefore Fe could be used to replace other $\beta$ stabilising elements at a lower cost [34].

The Ti-Fe binary phase diagram (Fig. 2) shows that $\mathrm{Fe}$ is a $\beta$-eutectoid stabiliser and therefore has limited solubility in both $\mathrm{Ti}$ phases as it forms an intermetallic TiFe phase [35]. This phase is brittle and so formation must be avoided to prevent poor mechanical performance. Despite formation of TiFe being thermodynamically favourable, it is a kinetically slow process and therefore can be avoided using a sufficient cooling rate from the $\beta$ region [36].

In this study, the proposed two-step FFC-Cambridge process coupled with the FAST processing route presents an opportunity to create high Fe content $\mathrm{Ti}$ alloys, which after further large-scale development, may be able to replace pre-existing alloys and reduce the cost of Ti alloy components. Exploiting a cheaper feedstock in SR further contributes to cost reduction and reduces reliance on alloying additions. SR contains remnant Fe from precursor ilmenite which becomes an alloying element once reduced. Enhancing this Fe content is possible by coreducing SR with $\mathrm{Fe}_{2} \mathrm{O}_{3}$ additions, as $\mathrm{Fe}_{2} \mathrm{O}_{3}$ can be reduced using the FFC-Cambridge process [37-39]. Therefore, this study investigates the co-reduction of SR and $\mathrm{Fe}_{2} \mathrm{O}_{3}$, followed by FAST consolidation, to produce a range of pseudo-binary $\mathrm{Ti}-\mathrm{Fe}$ alloys.
Material characterisation is performed at each stage and some final alloy properties are analysed.

\section{Materials and methods}

\section{Synthetic rutile $+\mathrm{Fe}_{2} \mathrm{O}_{3}$ oxide preparation}

Heat-treated synthetic rutile (provided by Iluka Resources, 150-212 $\mu \mathrm{m}$ ) and $\mathrm{Fe}_{2} \mathrm{O}_{3}$ (Sigma-Aldrich, $<5 \mu \mathrm{m},>99 \%$ ) powders were mixed using a Turbular mixer for $1 \mathrm{~h}$. Five different oxide compositions were made in addition to undoped SR, containing 1 , 2.5, 5, 7.5 and 10 wt. $\% \mathrm{Fe}_{2} \mathrm{O}_{3}$.

\section{Reduction of mixed oxides via the FFC- Cambridge process and post-processing}

Reductions were carried out using $20 \mathrm{~g}$ of each oxide composition, using $R \& D$ scale cells at Metalysis. Figure 3 shows a schematic of the reduction cells used. The same electrolysis parameters were used as in previous work where SR was successfully reduced to a titanium alloy containing $4000 \mathrm{ppm} \mathrm{O}$, except that a longer reduction time of $18 \mathrm{~h}$ was used after initial experiments showed a further reduction $\mathrm{O}$ levels [26].

$1.6 \mathrm{~kg}$ of dried $\mathrm{CaCl}_{2}$ with $\mathrm{CaO}(0.4$ wt.\%) was placed into a ceramic crucible within a steel retort. The oxide was placed into a steel basket lined with a stainless steel mesh. The cell was then sealed and
Figure 2 Ti-Fe phase diagram calculated using Thermocalc TTTI3 database [35].






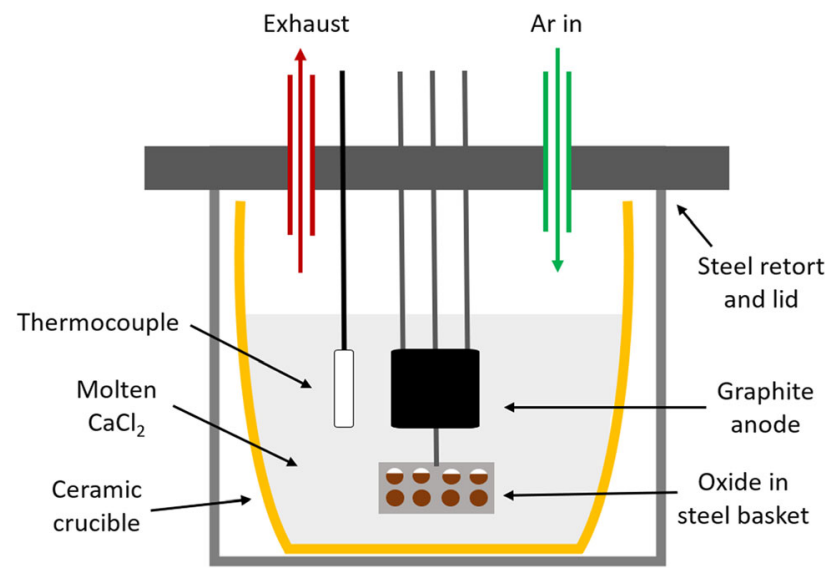

Figure 3 Schematic of FFC reduction cell used.

heated to $950{ }^{\circ} \mathrm{C}$ to melt the salt. Argon was continuously flushed through to create an inert atmosphere and remove gaseous by-products. The basket and graphite anode were then submerged into the molten salt electrolyte and the electrolysis began. A constant current of $5 \mathrm{~A}$ is applied following an initial ramp which prevents high voltages and decomposition of the electrolyte. The corresponding voltage therefore fluctuates to maintain the constant current. Exhaust gases were monitored using mass spectrometry to follow reduction progress and confirm that no $\mathrm{Cl}_{2}$ formation occurs. Reductions were performed for $18 \mathrm{~h}$ and the basket raised out of the salt. Once cool, the basket was removed from the cell and the material inside post-processed. This involved soaking in water followed by light grinding into a powder. The powder was then soaked in a solution of dilute aqua regia, washed with water and dried in a vacuum furnace at $80^{\circ} \mathrm{C}$. The resulting powders were then sieved to a size range of $75-212 \mu \mathrm{m}$ and ready for analysis and consolidation.

\section{Consolidation of Ti alloy powders}

The alloy powders were consolidated using FAST with an FCT Systeme GmbH type HP D25 spark plasma sintering furnace. Powders were placed within a graphite mould set, lined with graphite foil for ease of removal. Optimised parameters included a $100{ }^{\circ} \mathrm{C} / \mathrm{min}$ ramp rate to a maximum temperature of $1100{ }^{\circ} \mathrm{C}$, followed by a dwell of $1 \mathrm{~h}$ at a pressure of $35 \mathrm{MPa} .5 \mathrm{~g}$ of powder was used in a $20 \mathrm{~mm}$ diameter mould to create a disc of around $3 \mathrm{~mm}$ height. The discs were then cut perpendicular to the compression direction to expose a surface for metallographic preparation and analysis.

\section{Characterisation techniques}

The feedstock, alloy powders and consolidated material were all analysed using various techniques. An FEI Inspect F50 scanning electron microscope (SEM), with an acceleration voltage of $20 \mathrm{keV}$, was used to view powder morphology and characterise the microstructure. An Oxford Instruments energydispersive X-ray spectrometer (X-EDS) was used alongside SEM to determine chemical compositions in specific regions. Interstitial element contents of $\mathrm{O}$, $\mathrm{N}$ and $\mathrm{C}$ were measured by an ELTRA ON-900 and an ELTRA CS-800. Bulk alloy chemistry was measured by X-ray fluorescence (XRF) using a PANalytical Zetium, with a mean average of 3 results taken. Phase analysis was done using X-ray diffraction (XRD) using a Bruker D2 Phaser with $\mathrm{Cu}-\mathrm{K} \alpha$ radiation. Porosity was measured using a high-resolution mosaic of a $10 \mathrm{~mm}^{2}$ area, taken with an Olympus BX51 optical microscope. A colour threshold was then applied to leave only the porosity visible and the percentage area was measured using ImageJ software [40].

\section{Microhardness testing}

Vickers hardness measurements were carried out using a Struers Durascan-80, with a force of $5 \mathrm{~kg}$ (HV5), held for $15 \mathrm{~s}$. A $5 \times 5$ grid of 25 measurements was tested, covering an area of $10 \mathrm{~mm}^{2}$ in the centre of each sample. The mean average hardness was calculated, along with $95 \%$ confidence intervals on the means.

\section{Results and discussion}

\section{Characterisation of synthetic rutile and $\mathrm{Fe}_{2} \mathrm{O}_{3}$ powders prior to electrolytic reduction}

Elemental analysis of the SR was used to determine the alloying elements expected to be present in the reduced powders. X-ray fluorescence (XRF) data revealed that it contained approximately $4 \mathrm{wt} . \% \beta$ stabilising elements, mainly $\mathrm{Fe}$, and $<1$ wt.\% Al. Therefore, it would be expected that the resulting 
alloy will also contain these elements and so will have significant $\beta$ stabilisation compared to pure Ti.

Figure 4 shows that the SR particles vary in both size and morphology. The particles exhibit significant porosity, due to the conversion from the precursor ilmenite ore. XRD analysis determined that the heattreated SR consisted of two major phases, with all peaks being assigned to $\mathrm{TiO}_{2}$ (rutile) or $\mathrm{Fe}_{2} \mathrm{TiO}_{5}$ (pseudobrookite) (Fig. 5). Although the $\mathrm{Fe}_{2} \mathrm{TiO}_{5}$ phase is only present in small amounts, it is visible in backscattered SEM as brighter $\mathrm{Z}$ contrast regions due to its higher density. Mixing the SR with $\mathrm{Fe}_{2} \mathrm{O}_{3}$ caused the much finer $\mathrm{Fe}_{2} \mathrm{O}_{3}$ particles to adhere to the surfaces of the SR, though this was not uniform due to the angular morphology of the particles. Some particles were coated with greater amounts of $\mathrm{Fe}_{2} \mathrm{O}_{3}$ than others, which was expected to lead to significant chemical heterogeneity in the material postreduction.

\section{Characterisation of $\mathrm{Ti}-\mathrm{xFe}$ alloy powders}

Figure 6 shows that the resulting powders exhibited a variation of sizes and morphologies, which is

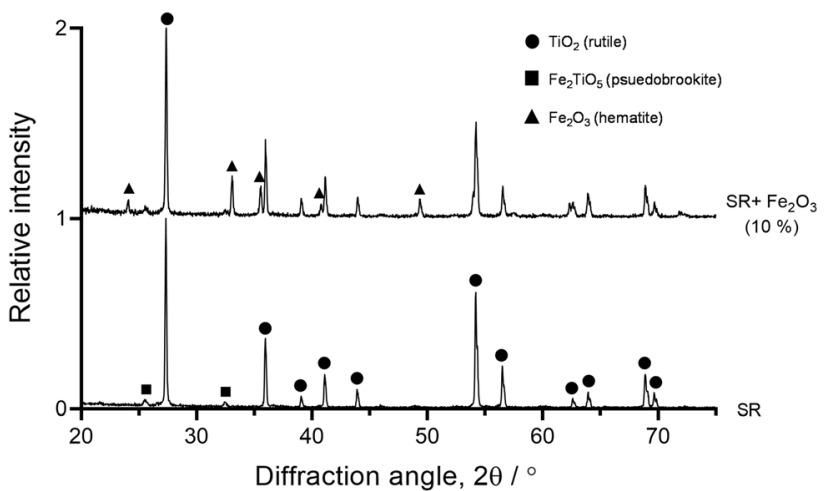

Figure $5 \mathrm{XRD}$ patterns $\mathrm{SR}$ and $\mathrm{SR}+\mathrm{Fe}_{2} \mathrm{O}_{3}(10 \mathrm{wt} . \%)$ mixture.

typical for milled powders such as those derived from the hydride-dehydride process. Some internal porosity was still present, although it had noticeably reduced during the reduction from the initial SR powder. No features were visible within the pores, suggesting that they did not contain any material, however any gases present would have been released once exposed from metallographic preparation. Microstructural variation was seen between particles, suggesting significant chemical heterogeneity as predicted due to non-uniform coating of $\mathrm{Fe}_{2} \mathrm{O}_{3}$.
Figure 4 Backscattered electron micrographs of: a SR particle, $\mathbf{b}$ SR particle with surface $\mathrm{Fe}_{2} \mathrm{O}_{3}$, c SR $+\mathrm{Fe}_{2} \mathrm{O}_{3}$ particles, d X-EDS element map of the $\mathrm{c}$ showing Ti (blue) and $\mathrm{Fe}$ (red).
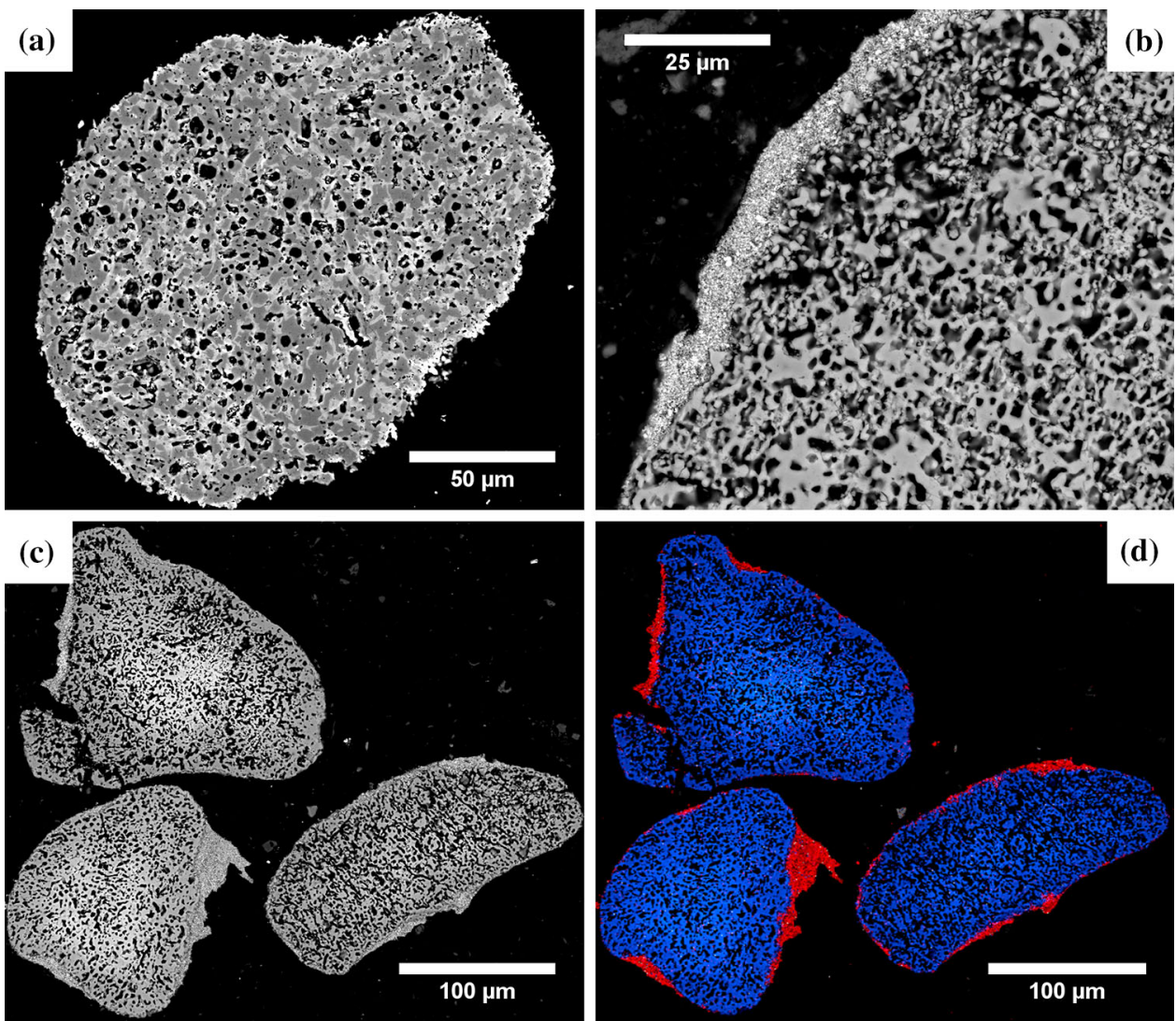
Figure 6 Backscattered electron micrographs of reduced $\mathrm{Ti}-\mathrm{xFe}$ alloy powders, derived from a range of $\mathrm{SR}+\mathrm{Fe}_{2} \mathrm{O}_{3}$ mixtures. a: range of powder particles (powder sample from 4.64 wt.\% Fe alloy - see Table 1), b: $\alpha$-rich and $\beta$-rich particles (6.21 wt.\% Fe), c: particles with $\alpha+\beta$ microstructures (3.41 wt.\% Fe), d: $\beta$ stabilised particle containing brighter TiFe phase $(9.03$ wt.\% Fe).
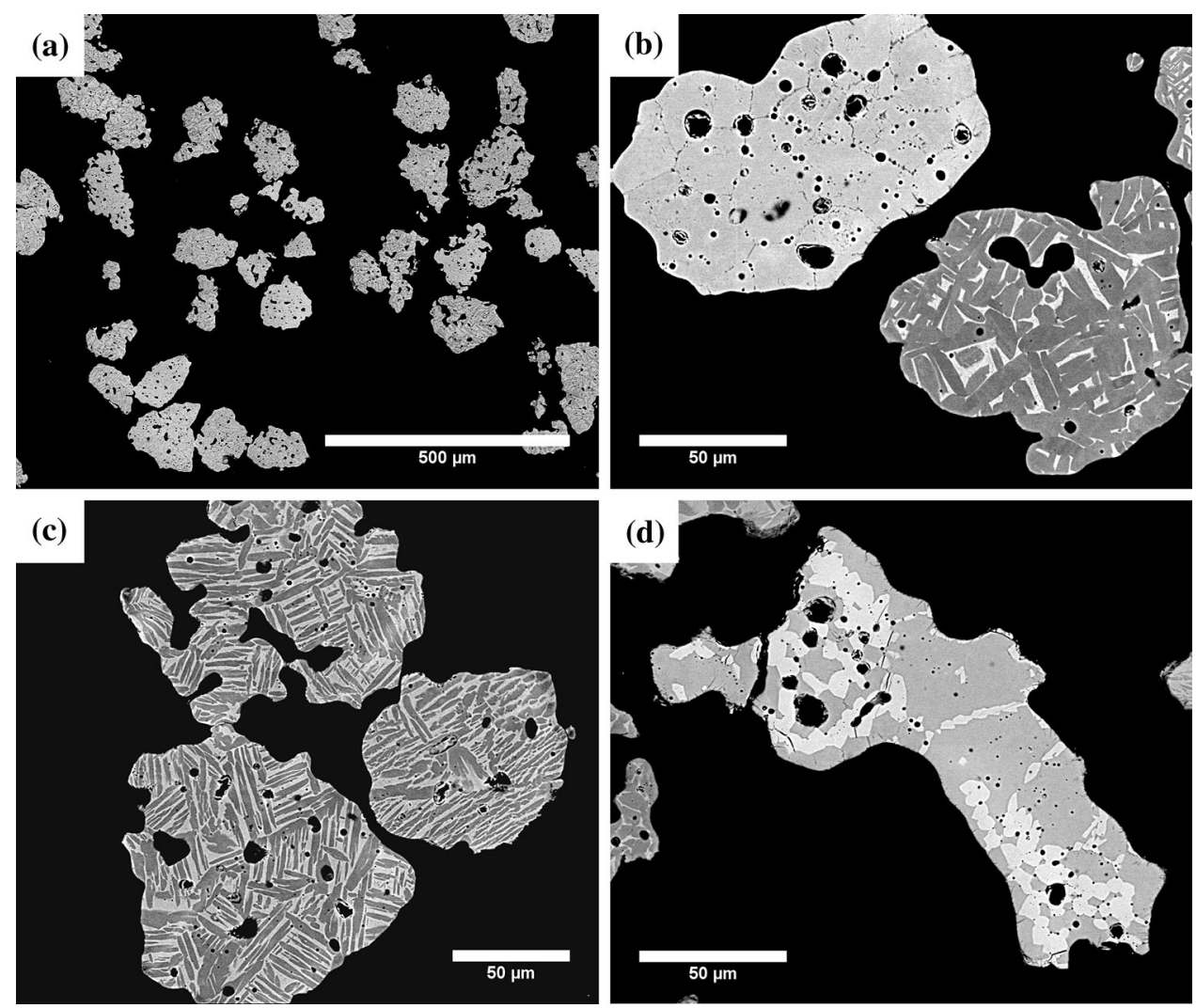

Figure 6a-c shows examples of the types of particles observed in all samples, including $\alpha$-rich, $\alpha+\beta$ and $\beta$-rich microstructures. A few particles in the powders derived from 7.5 and 10 wt. $\% \mathrm{Fe}_{2} \mathrm{O}_{3}$ oxide compositions contained a third phase, determined by $\mathrm{X}$-EDS to be intermetallic TiFe (Fig. 6d). These particles therefore must have originally had more $\mathrm{Fe}_{2} \mathrm{O}_{3}$ locally and so contained enough $\mathrm{Fe}$ to retain the TiFe phase on completion of the reduction. No $\mathrm{TiFe}_{2}$ or metallic $\mathrm{Fe}$ was observed in the final powders, although these will have formed during early stages of the reduction, before further Fe diffusion into the Ti matrix [26].

The interstitial $\mathrm{O}$ and $\mathrm{C}$ contents of the powders were measured at this stage (Table 1), whereas $\mathrm{Fe}$ content was measured post-consolidation (discussed later). $O$ contents had a range of around 2000 ppm (1668-3745 ppm), which is significant for Ti alloys. $\mathrm{O}$ is a potent $\alpha$ stabilising element and small variations considerably affect mechanical properties. For example, alloy grades 1 to 4 differ in max $\mathrm{O}$ content by just $0.22 \mathrm{wt} \%$, but yield strengths can vary from about $170-480 \mathrm{MPa}$ [41]. The increase in strength causes decreased ductility and so Ti alloys typically do not exceed $0.4 \mathrm{wt}$.\% O.
There are many potential reasons for this variation, including slight deviations in process parameters between reductions, the use of multiple reduction cells and inherent inconsistencies in manual postprocessing of the powders. There seems to be no correlation between residual $\mathrm{O}$ content and oxide composition used, suggesting it has no significant effect, but this may be concealed by the other influencing variables.

C contents also varied; with C pickup occurring during the reduction process due to degradation of the graphite anode. Loose $\mathrm{C}$ covers the surface of the reducing material and some diffuses into $\mathrm{Ti}$ solid solution. For this small-scale reduction, the relative surface area of the powder exposed to this material is high, causing higher than desirable $C$ levels. Such levels can be reduced when scaling up the process, due to a lower relative surface area. Thorough washing of the material after removal from the cell removes most of the $\mathrm{C}$ pickup, although this is limited, especially when done manually. Some $\mathrm{C}$ may be present on the surface of the particles, but this was not observable using SEM as the samples were mounted in conductive bakelite. $\mathrm{C}$ is also an $\alpha$ stabiliser but only has a maximum solubility of 0.48 
Table $1 \mathrm{O}, \mathrm{C}$ and $\mathrm{Fe}$ contents of the reduced $\mathrm{Ti}-\mathrm{xFe}$ alloys with corresponding oxide compositions. $\mathrm{O}$ and $\mathrm{C}$ measured directly from powder, $\mathrm{Fe}$ measured by XRF from bulk material postconsolidation

\begin{tabular}{llll}
\hline Oxide $\mathrm{Fe}_{2} \mathrm{O}_{3}$ content / wt.\% & $\mathrm{O} / \mathrm{ppm}$ & $\mathrm{C} / \mathrm{ppm}$ & $\mathrm{Fe} / \mathrm{wt} . \%$ \\
\hline 0 & 3460 & 1519 & 1.84 \\
1 & 3351 & 927 & 2.22 \\
1 & 2238 & 1467 & 3.65 \\
2.5 & 2224 & 1424 & 3.41 \\
2.5 & 2742 & 1189 & 5.15 \\
5 & 1668 & 1256 & 6.21 \\
5 & 3682 & 1619 & 8.02 \\
7.5 & 1934 & 774 & 4.64 \\
7.5 & 1891 & 832 & 7.19 \\
10 & 3745 & 896 & 9.03 \\
\hline
\end{tabular}

wt. $\%$ in the $\alpha$ phase at $920{ }^{\circ} \mathrm{C}$ [42]. It therefore forms a ceramic phase (TiC) on cooling, even at low concentrations. This carbide phase is brittle and therefore undesirable in the alloys. No evidence of carbide was seen in the powder micrographs, suggesting $C$ levels were sufficiently low to prevent formation.

\section{Consolidation of Ti-xFe alloy powders by field-assisted sintering}

The chemical heterogeneity, angularity and porosity of these powders make them unsuitable for powder metallurgy techniques such as additive manufacturing, where a defined level of sphericity and powder size is required. In contrast, FAST is far more flexible with respect to input powder feedstock, as demonstrated by a successful study on directly consolidating irregular machining swarf particulate [43]. Therefore, it can process these powders without issues to create alloy billets for subsequent forging and/or finish machining. Optimisation of the FAST process was necessary for these powders to ensure chemical homogeneity and uniform microstructures. Although FAST can sinter powder within minutes, longer dwell times are required in this case to facilitate the necessary solid-state diffusion. Fe rapidly diffuses in $\mathrm{Ti}$ and is known to enhance sintering, therefore the parameters could be relatively moderate [44].

Initial consolidation of the powder was achieved based on previous FAST processing of SR derived alloy powders, using a dwell temperature of $1000{ }^{\circ} \mathrm{C}$ for $30 \mathrm{~min}$. Figure 7 shows that these conditions were insufficient for complete diffusion, as localised regions of $\alpha$ and $\beta$ remained. These were likely due to larger particles which were particularly rich or deficient in Fe, such as those in Fig. 6b. After an investigation on the effects of both temperature and dwell time, it was found that a dwell at $1100{ }^{\circ} \mathrm{C}$ for $60 \mathrm{~min}$ was able to produce homogeneous microstructures. Higher temperatures and longer dwell times are expected to have the same effect but would be unnecessary, costly, and could cause undesirable grain growth. Figure 8 shows a profile of the FAST process, using these optimised conditions. Sintering is achieved within around $10 \mathrm{~min}$, while the system ramps to maximum temperature. Diffusion then continues during the dwell, followed by uncontrolled cooling to room temperature and thermal contraction to final volume.

\section{Analysis of consolidated Ti-xFe alloys}

Elemental compositions of the bulk alloys were determined using $\mathrm{XRF}$, showing that alloys with a range of Fe contents from 1.84 to 9.03 wt.\% were produced (Table 1). The final Fe contents do not correspond well with the initial oxide compositions, indicating that significant amounts of $\mathrm{Fe}$ were lost during the reduction process. Figure 9 shows the comparison of oxide composition against final $\mathrm{Fe}$ content. Previous work on reducing SR using the FFC-Cambridge process has shown that the Fe content in the alloy is approximately 0.5 times the theoretical maximum [45]. Therefore, this was expected to some degree, although it was unknown exactly how the $\mathrm{Fe}_{2} \mathrm{O}_{3}$ would react during the reduction compared to $\mathrm{Fe}_{2} \mathrm{TiO}_{5}$.

The loss of Fe must occur physically and/or chemically. Given the $\mathrm{Fe}_{2} \mathrm{O}_{3}$ is only loosely coating the surface of the SR particles, it is likely that some separation occurs on submersion of the oxide into the molten salt. It is also possible that there is a side reaction of the salt with the $\mathrm{Fe}_{2} \mathrm{O}_{3}$ and the $\mathrm{Fe}_{2} \mathrm{TiO}_{5}$, which causes leaching of the $\mathrm{Fe}$ and thus reduces the expected content in the resulting alloy. This requires further understanding to accurately predict alloy chemistry from oxide composition; however, this was beyond the scope of this study. The inconsistencies in the process are unideal, yet this oxide mixture has not been investigated previously and so it is anticipated more consistent results can be achieved in the future, 
Figure 7 Backscattered electron micrographs of initial FAST consolidation of 4.64 wt. $\% \mathrm{Fe}$ alloy at $1000{ }^{\circ} \mathrm{C}$ with a 30 min dwell, showing local regions of high $\alpha$ (left) and high $\beta$ (right) stabilisation.


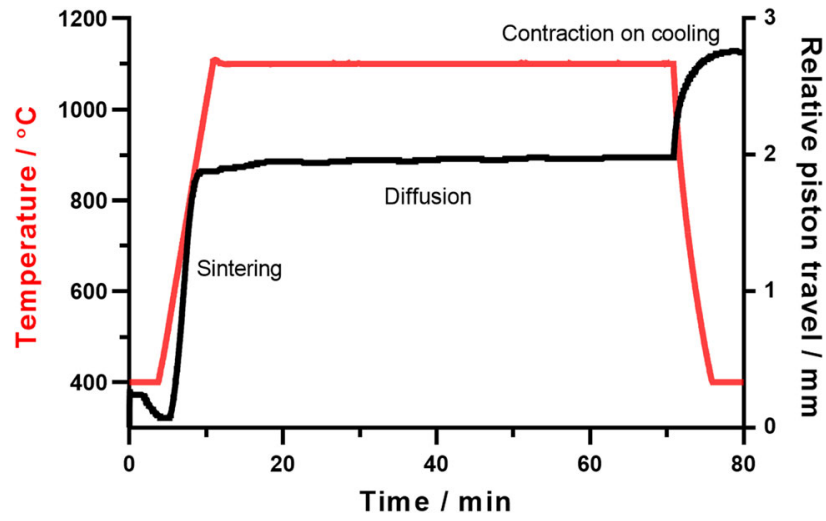

Figure 8 Temperature profile of FAST processing at $1100{ }^{\circ} \mathrm{C}$ with a $60 \mathrm{~min}$ dwell and powder consolidation behaviour, indicated by the relative movement of the graphite punches.

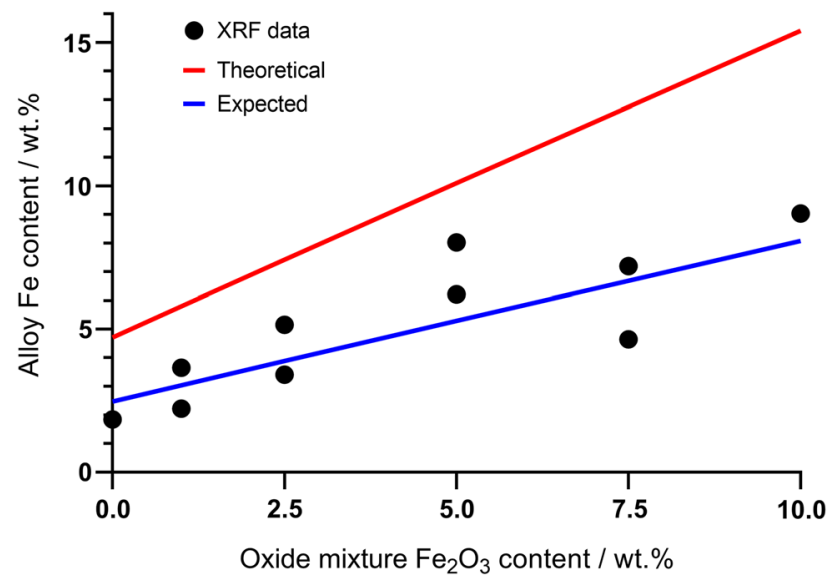

Figure $9 \mathrm{Fe}$ contents of reduced alloys compared with initial oxide mixtures, calculated theoretical and expected $(52 \%$ theoretical) Fe contents also shown.

via improved mixing and better adhesion of the surface layer. Heat treatment of the oxide mixture may also improve mixing and Fe retention through diffusion and formation of the $\mathrm{Fe}_{2} \mathrm{TiO}_{5}$ phase at the surfaces of the SR particles.

Alloying elements aside from Fe were also detected by $\mathrm{XRF}$, as was expected from the impurities in the SR feedstock, with $\mathrm{Al}, \mathrm{Si}, \mathrm{Mn}$ and $\mathrm{Nb}$ contents between 0.2-0.5 wt.\% and consistent between each alloy. $\mathrm{Cr}$ contents were significantly higher than would be expected from the SR alone, varying from $0.61-2 \mathrm{wt} . \%$. It is therefore presumed that Cr pickup occurs due to contamination from the stainless steel mesh in which the oxide sits during electrolysis. Further investigation and use of a different mesh material would be required to confirm this. The presence of these elements will affect the microstructure due to their differing effects on $\alpha$ and $\beta$ stabilisation. Therefore, despite some $\alpha$ stabilisation from the $\mathrm{Al}$, this should cause an overall slight increase in $\beta$ stability compared to that from the $\mathrm{Fe}$ alone.

Although no $\mathrm{CaCl}_{2}$ residue was observed on analysis of the powders, both $\mathrm{Ca}$ and $\mathrm{Cl}$ were detected at around $0.2 \mathrm{wt} . \%$ in all the alloys. While some Ca may have been retained from the SR, this suggests that some electrolyte contamination was present despite washing of the powders. More thorough grinding and washing of the powders during post processing could prevent this. It is unknown exactly what effect FAST processing would have on any $\mathrm{CaCl}_{2}$ contamination, however formation of $\mathrm{Cl}_{2}$ gas, which could become trapped as porosity within the material, is probable and requires further investigation.

Figure 10 shows how the microstructure of the alloys varies with increasing $\mathrm{Fe}$ content. At lower $\mathrm{Fe}$ contents, $\alpha+\beta$ microstructures are observed, 

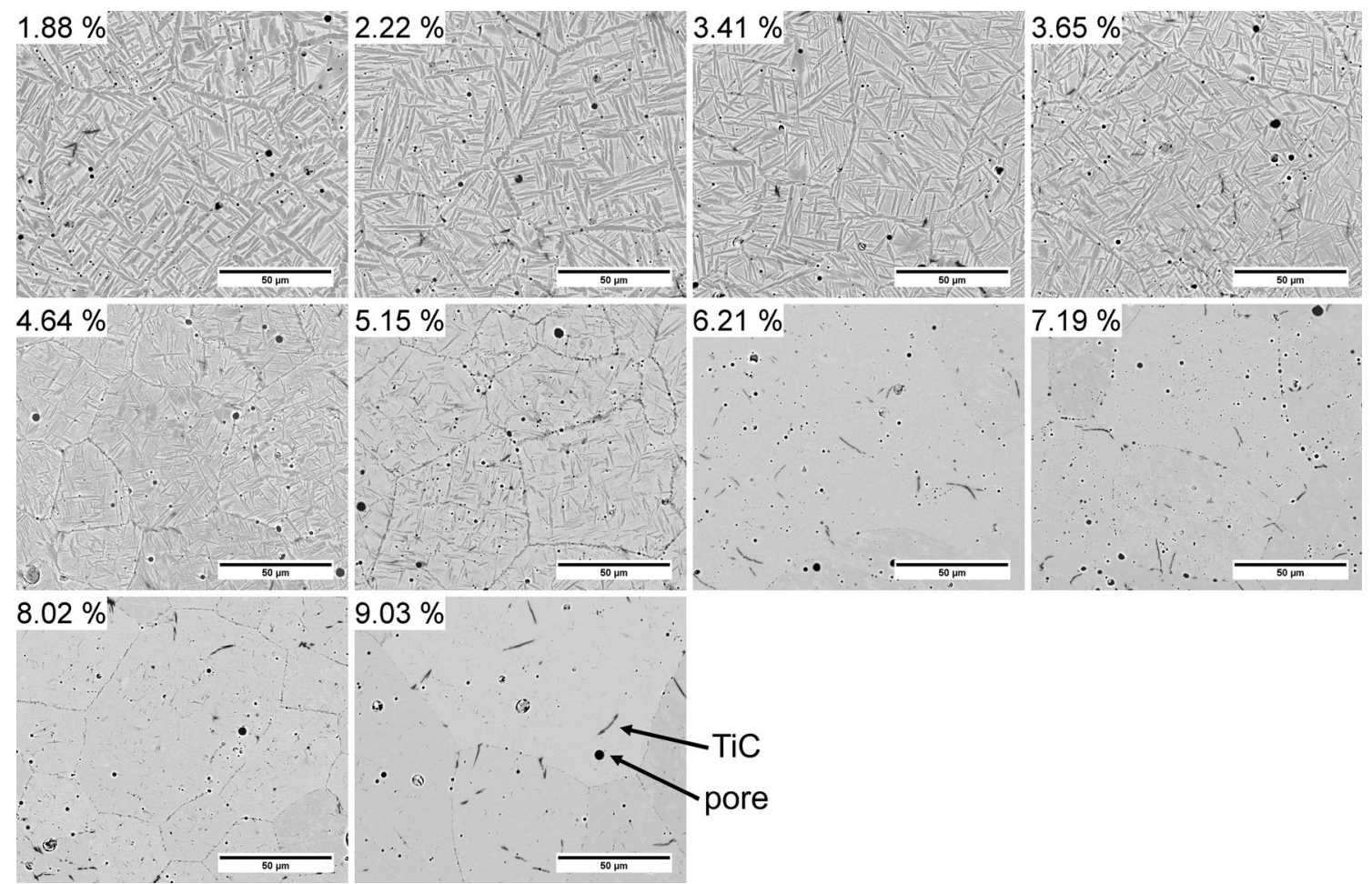

Figure 10 Backscattered electron micrographs of Ti-xFe consolidated alloys, in order of increasing Fe content, wt.\% (labelled).

comprising of coarse $\alpha$ laths with fine secondary $\alpha$ between them. Equiaxed prior $\beta$ grains are clearly identifiable as the grain boundaries are decorated with $\alpha$. With increasing Fe content, the $\alpha$ laths reduce in size until only the $\beta$ phase remains. A small amount of $\alpha$ phase was seen in the 8.02 wt.\% $\mathrm{Fe}$ sample, although this sample does have a relatively high $\mathrm{O}$ content which explains this. No intermetallic TiFe phase was seen post-FAST, despite being present in some of the powders. This confirms that there was sufficient diffusion to allow the Fe from this phase to fully dissolve into the Ti matrix. Although some porosity remains, likely due to internal porosity in the original powder particles (Fig. 6) or $\mathrm{Cl}_{2}$ formation, all samples were found to have a density $>99 \%$.

Small amounts of TiC are seen after consolidation, visible as thin black needles in the SEM micrographs. These needles were not seen in the powders which suggests that the FAST process has caused them to precipitate out from solid solution, or that residual C was coating the powder particles rather than being present internally. C pickup is known to occur during FAST, resulting from use of a graphite mould setup which is in contact with the powder. A previous study has shown this to be around 100-200 ppm; however, it may be more significant here due to the lower mass of powder used and larger relative surface area exposed to the graphite foil [27]. Further research is required to better understand $C$ contamination and the formation of the $\mathrm{TiC}$ phase through this production route.

XRD patterns for the alloys complement well with the microstructures in Fig. 10, as there is a clear increase in the ratio of $\beta: \alpha$ intensities with increasing Fe content (Fig. 11). From 6.21 wt.\% Fe, $\alpha$ peaks are no longer detected, confirming single phase $\beta$ alloys. This shows that, under these processing conditions, the formation of fully $\beta$ alloys becomes favourable between 5.15 and $6.21 \mathrm{wt}$ \% Fe, but other factors also affect the microstructure, such as the presence of other alloying elements and interstitial contents. Although some $\alpha$ was possibly present in the micrograph from the $8.02 \mathrm{wt} . \%$ sample, no corresponding peaks were measured from XRD, suggesting that $\alpha$ content was minimal. Despite TiC needles being observed in the SEM micrographs, the corresponding XRD peaks were not visible, indicating that this phase must only be present in a very small amount. This agrees with the $C$ analysis of the powders which all showed $<2000 \mathrm{ppm}$ which prevents significant carbide formation. Therefore, it is not expected that 


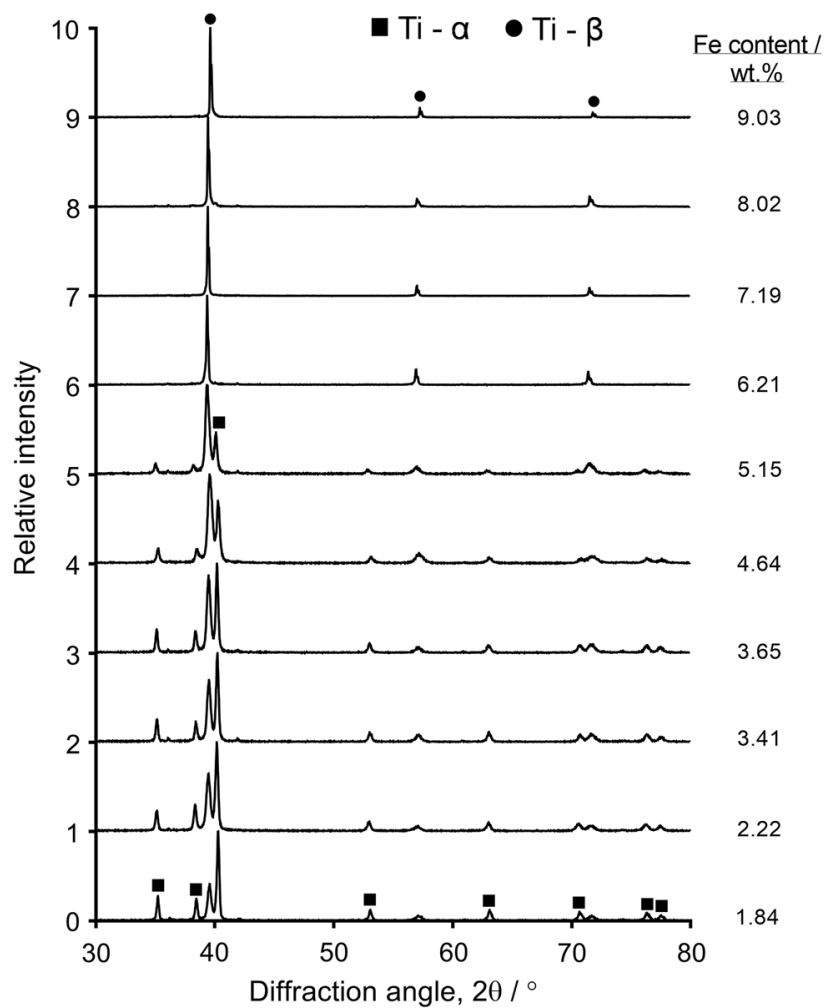

Figure 11 XRD patterns of consolidated Ti-xFe alloys, with increasing $\mathrm{Fe}$ content.

this phase will have noticeable impacts on the mechanical properties of the alloys.

The samples made on this scale were not large enough to perform a thorough assessment of their mechanical properties; however, microhardness testing was performed to determine any effects of increasing Fe content and varying microstructures. Figure 12 shows that there is not a simple relationship between the Fe content and hardness. The hardness values seem to increase up to a maximum of around $400 \mathrm{Hv}$ for the 5.15 wt.\% alloy, before dropping down to around $340 \mathrm{Hv}$. This is likely due to the strengthening effect of finer $\alpha$ laths that have precipitated on cooling during the FAST process, which are not present at Fe contents $>5.15$ wt. $\%$. Fine-scale $\alpha$ formation is known to increase alloy strength by creating more $\alpha / \beta$ interfaces which block dislocation movement $[46,47]$. The general trend of increasing hardness can be attributed to solid solution strengthening, as more Fe is being forced into the Ti matrix. Again, there are other factors to consider besides Fe content which can affect the hardness. O content has a dramatic effect on the strength of $\mathrm{Ti}$ alloys and therefore it is difficult to compare these

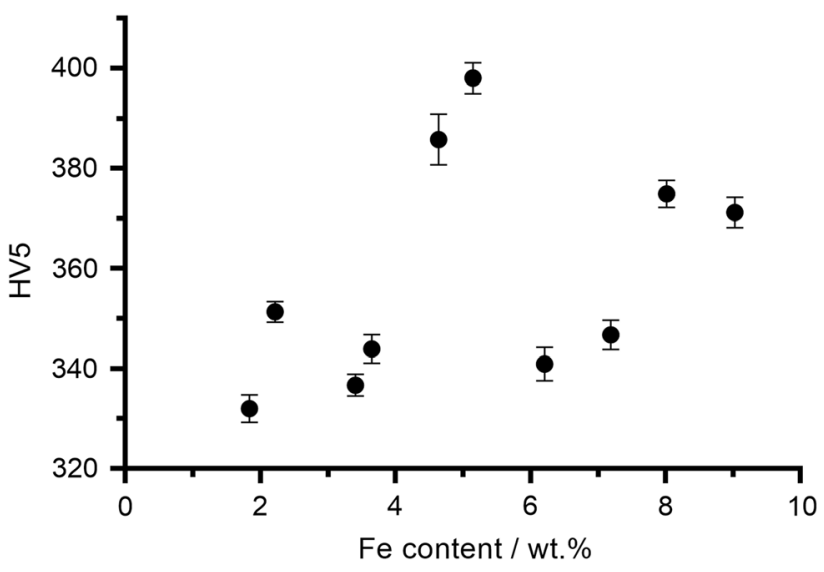

Figure 12 Vickers hardness of the consolidated Ti-xFe alloys.

alloys when they have varying $\mathrm{O}$ contents. Despite this, no correlation was found between the $\mathrm{O}$ content of the alloys and their hardness, with an $\mathrm{R}^{2}$ value of 0.03 .

\section{Conclusions}

Overall, this study has once again demonstrated the flexibility of the FFC-Cambridge process for co-reducing mixed metal oxides to directly produce alloys. Co-reduction of synthetic rutile (SR) and $\mathrm{Fe}_{2} \mathrm{O}_{3}$ produced a range of pseudo-binary $\mathrm{Ti}-\mathrm{Fe}$ alloys, presenting the possibility of using unconventional and cheaper feedstocks in the process to create lower cost Ti alloys. After optimisation, FAST enabled the consolidation of the alloy powders and the diffusion required to create homogeneous material. A range of microstructures was observed, from $\alpha+\beta$ to fully $\beta$, with $\alpha$ phase no longer detected at a concentration between 5.15 and 6.21 wt.\% Fe. Fe contents up to 9.03 wt.\% were achieved without any intermetallic formation, with further work required to discover the limit of Fe solubility in Ti under these conditions.

The inconsistencies in the experiments, along with the many variables involved, made alloy comparisons and reproducibility of results difficult. Predicting final alloy composition is challenging, due to poor understanding of the mechanism of Fe loss during reduction and pickup of $\mathrm{Cr}$. Contents of the remnant elements from the $\mathrm{SR}$, mainly $\mathrm{Al}, \mathrm{Si}, \mathrm{Mn}$ and $\mathrm{Nb}$, were consistent across the alloys, however.

Interstitial contents also varied between the alloys, due to slight variations in both the reductions and post-processing of the material on this small scale. 
Nevertheless, this oxide mixture has not been investigated previously, and so it is anticipated that future improvements could solve these issues. For example, more effective mixing of the oxides should improve Fe retention and, consequently, the predictability of alloy composition. This could be done by mixing using a binder, or perhaps by heat-treating the mixture to chemically bind the oxides together as $\mathrm{Fe}_{2-}$ $\mathrm{TiO}_{5}$. Improved mixing should also make the resulting alloy powders more chemically homogeneous, allowing for complete diffusion to be achieved using a shorter FAST dwell duration.

Interstitial content variation could also be reduced by altering aspects of the extraction process. Optimisation of the FFC-Cambridge process for this oxide mixture could further reduce $\mathrm{O}$ contents and lower the range between powders. Automated post-processing of the powders would assist in the removal of surface $C$, decreasing variation in $C$ contents and preventing any carbide formation. The use of inert anodes in the FFC-Cambridge process would remove $\mathrm{C}$ from the system entirely, producing $\mathrm{O}_{2}$ gas instead and improving current efficiency [20, 48]. Future developments will be monitored, but currently only a few materials have shown promise as inert anodes in the FFC-Cambridge process, and more research is required to assess their longevity over many reduction cycles.

The quantities of the alloy powders generated meant that mechanical testing was limited to microhardness only. These data suggested that there are two main strengthening effects which increase the hardness values: solid solution strengthening from increasing $\mathrm{Fe}$ content and the precipitation of fine secondary $\alpha$ on cooling. Further assessment of the mechanical properties of these alloys is an important next step in understanding their potential as materials. This involves generating greater quantities of powder to produce larger FAST billets from which various specimens can be machined. Conventional $\mathrm{Ti}$ alloy powders consolidated using the same FAST conditions can then be tested for comparisons. Binary Ti-Fe alloys can also be produced using FAST from blended elemental powders, giving far greater control over Fe content. Investigating this would allow for comparisons with these $\mathrm{SR}+\mathrm{Fe}_{2} \mathrm{O}_{3}$ derived alloys to understand any effects of production via the FFC-Cambridge process and the presence of other remnant elements from the SR.

\section{Acknowledgements}

The authors acknowledge Metalysis and the Engineering and Physical Sciences Research Council, grant EP/L016273 Centre for Doctoral Training in Advanced Metallic Systems, for supporting this research. The authors also acknowledge support by the Henry Royce Institute for Advanced Materials, funded through EPSRC grants EP/R00661X/1, EP/ S019367/1, EP/P02470X/1 and EP/P025285/1. Many thanks also go to Ben Thomas and Nick Weston for FAST assistance, and staff at Metalysis for their contributions and support: Claire Seddon, Joe Hardman, Nader Khan, Sarah Boot, Basharat Ali, Stephen Repper, Luke Marshall and Ian Mellor.

\section{Compliance with ethical standards}

Conflict of interest Author Lyndsey Benson was an employee of Metalysis during the majority of this study.

Open Access This article is licensed under a Creative Commons Attribution 4.0 International License, which permits use, sharing, adaptation, distribution and reproduction in any medium or format, as long as you give appropriate credit to the original author(s) and the source, provide a link to the Creative Commons licence, and indicate if changes were made. The images or other third party material in this article are included in the article's Creative Commons licence, unless indicated otherwise in a credit line to the material. If material is not included in the article's Creative Commons licence and your intended use is not permitted by statutory regulation or exceeds the permitted use, you will need to obtain permission directly from the copyright holder. To view a copy of this licence, visit http://creativecommons.org/licen ses/by/4.0/.

\section{References}

[1] Chen GZ, Fray DJ, Farthing TW (2000) Direct electrochemical reduction of titanium dioxide to titanium in molten calcium chloride. Nature 407:361-364. https://doi.org/10.1 038/35030069

[2] Barnett R, Kilby KT, Fray DJ (2009) Reduction of tantalum pentoxide using graphite and tin-oxide-based anodes via the FFC-Cambridge process. Metall Mater Trans B 40:150-157. https://doi.org/10.1007/s11663-008-9219-6 
[3] Chen GZ, Gordo E, Fray DJ (2004) Direct electrolytic preparation of chromium powder. Metall Mater Trans B 35:223-233. https://doi.org/10.1007/s11663-004-0024-6

[4] Claux B, Serp J, Fouletier J (2011) Electrochemical reduction of cerium oxide into metal. Electrochim Acta 56:2771-2780. https://doi.org/10.1016/j.electacta.2010.12. 040

[5] Bhagat R, Jackson M, Inman D, Dashwood R (2009) Production of Ti-W alloys from mixed oxide precursors via the FFC Cambridge process. J Electrochem Soc 156:E1. http s://doi.org/10.1149/1.2999340

[6] Bhagat R, Jackson M, Inman D, Dashwood R (2008) The production of Ti-Mo alloys from mixed oxide precursors via the FFC Cambridge process. J Electrochem Soc 155:E63E69. https://doi.org/10.1149/1.2904454

[7] Jackson BK, Inman D, Jackson M, Dye D, Dashwood RJ (2010) NiTi production via the FFC Cambridge process: refinement of process parameters. J Electrochem Soc 157:E36-E43. https://doi.org/10.1149/1.3289996

[8] Sure J, Vishnu DSM, Schwandt C (2017) Direct electrochemical synthesis of high-entropy alloys from metal oxides. Appl Mater Today 9:111-121. https://doi.org/10.1016/j.apm t.2017.05.009

[9] Lomax BA, Conti M, Khan N, Bennett NS, Ganin AY, Symes MD (2020) Proving the viability of an electrochemical process for the simultaneous extraction of oxygen and production of metal alloys from lunar regolith. Planet Space Sci 180:104748. https://doi.org/10.1016/j.pss.2019.104748

[10] Schwandt C, Fray DJ (2005) Determination of the kinetic pathway in the electrochemical reduction of titanium dioxide in molten calcium chloride. Electrochim Acta 51:66-76. h ttps://doi.org/10.1016/j.electacta.2005.03.048

[11] Fray DJ, Chen GZ (2004) Reduction of titanium and other metal oxides using electrodeoxidation. Mater Sci Technol 20:295-300. https://doi.org/10.1179/026708304225012242

[12] Mohandas KS, Fray DJ (2009) Electrochemical deoxidation of solid zirconium dioxide in molten calcium chloride. Metall Mater Trans B 40:685-699. https://doi.org/10.1007/ s11663-009-9263-x

[13] Schwandt C, Fray DJ (2007) The electrochemical reduction of chromium sesquioxide in molten calcium chloride under cathodic potential control. Z Für Naturforschung A. https://d oi.org/10.1515/zna-2007-10-1115

[14] Sri Maha Vishnu D, Sanil N, Shakila L, Panneerselvam G, Sudha R, Mohandas KS, Nagarajan K (2013) A study of the reaction pathways during electrochemical reduction of dense $\mathrm{Nb}_{2} \mathrm{O}_{5}$ pellets in molten $\mathrm{CaCl}_{2}$ medium. Electrochim Acta 100:51-62. https://doi.org/10.1016/j.electacta.2013.03.135

[15] Schwandt C, Alexander DTL, Fray DJ (2009) The electrodeoxidation of porous titanium dioxide precursors in molten calcium chloride under cathodic potential control. Electrochim Acta 54:3819-3829. https://doi.org/10.1016/j.electa cta.2009.02.006

[16] Schwandt C (2018) On the nature of the current and the absence of an IR-drop in an FFC-Cambridge-type electrodeoxidation cell. Electrochim Acta 280:114-120. https://doi. org/10.1016/j.electacta.2018.05.083

[17] Mellor I, Grainger L, Rao K, Deane J, Conti M, Doughty G, Vaughan D (2015) Titanium powder production via the metalysis process. In: Qian M, Froes FHS (eds) Titanium powder metallurgy. Butterworth-Heinemann, Boston, pp 51-67

[18] Norgate TE, Jahanshahi S, Rankin WJ (2007) Assessing the environmental impact of metal production processes. J Clean Prod 15:838-848. https://doi.org/10.1016/j.jclepro.2006.06. 018

[19] Hu D, Dolganov A, Ma M, Bhattacharya B, Bishop MT, Chen GZ (2018) Development of the fray-farthing-chen cambridge process: towards the sustainable production of titanium and its alloys. JOM 70:129-137. https://doi.org/10. 1007/s11837-017-2664-4

[20] Jiao S, Fray DJ (2010) Development of an inert anode for electrowinning in calcium chloride-calcium oxide melts. Metall Mater Trans B 41:74-79. https://doi.org/10.1007/s1 1663-009-9281-8

[21] Hu D, Xiao W, Chen GZ (2013) Near-net-shape production of hollow titanium alloy components via electrochemical reduction of metal oxide precursors in molten salts. Metall Mater Trans B 44:272-282. https://doi.org/10.1007/s11663013-9800-5

[22] Dolganov A, Bishop MT, Tomatis M, Chen GZ, Hu D (2020) Environmental assessment of the near-net-shape electrochemical metallisation process and the Kroll-electron beam melting process for titanium manufacture. Green Chem 22:1952-1967. https://doi.org/10.1039/C9GC04036F

[23] Ma M, Wang D, Wang W, Hu X, Jin X, Chen GZ (2006) Extraction of titanium from different titania precursors by the FFC Cambridge process. J Alloys Compd 420:37-45. http s://doi.org/10.1016/j.jallcom.2005.10.048

[24] Zhang W, Zhu Z, Cheng CY (2011) A literature review of titanium metallurgical processes. Hydrometallurgy 108:177-188. https://doi.org/10.1016/j.hydromet.2011.04. 005

[25] Becher RG, Canning RG, Goodheart BA, Uusna S (1965) A new process for upgrading ilmenitic mineral sands. Proc Aust Inst Min Met 214:21-44

[26] Benson LL, Mellor I, Jackson M (2016) Direct reduction of synthetic rutile using the FFC process to produce low-cost novel titanium alloys. J Mater Sci 51:4250-4261. https://doi. org/10.1007/s10853-015-9718-1 
[27] Weston NS, Derguti F, Tudball A, Jackson M (2015) Spark plasma sintering of commercial and development titanium alloy powders. J Mater Sci 50:4860-4878. https://doi.org/10. 1007/s10853-015-9029-6

[28] Weston NS, Jackson M (2017) FAST-forge-a new costeffective hybrid processing route for consolidating titanium powder into near net shape forged components. J Mater Process Technol 243:335-346. https://doi.org/10.1016/j.jma tprotec.2016.12.013

[29] Benson LL, Benson Marshall LA, Weston NS, Mellor I, Jackson M (2017) On a testing methodology for the mechanical property assessment of a new low-cost titanium alloy derived from synthetic rutile. Metall Mater Trans A 48:5228-5232. https://doi.org/10.1007/s11661-017-4333-1

[30] Mitchell A, Kawakami A, Cockcroft SL (2006) Beta fleck and segregation in titanium alloy ingots. High Temp Mater Process 25:337-349. https://doi.org/10.1515/HTMP.2006.2 5.5-6.337

[31] Esteban PG, Bolzoni L, Ruiz-Navas EM, Gordo E (2011) $\mathrm{PM}$ processing and characterisation of Ti-7Fe low cost titanium alloys. Powder Metall 54:242-252. https://doi.org/ 10.1179/174329009X457063

[32] Bolzoni L (2019) Low-cost Fe-bearing powder metallurgy Ti alloys. Met Powder Rep 74:308-313. https://doi.org/10.101 6/j.mprp.2019.01.007

[33] Reverte E, Tsipas SA, Gordo E (2020) Oxidation and corrosion behavior of new low-cost Ti-7Fe-3Al and Ti-7Fe-5Cr alloys from titanium hydride powders. Metals 10:254. http s://doi.org/10.3390/met10020254

[34] Kolli R, Devaraj A (2018) A review of metastable beta titanium alloys. Metals 8:506. https://doi.org/10.3390/me t8070506

[35] Andersson J-O, Helander T, Höglund L, Shi P, Sundman B (2002) Thermo-Calc \& DICTRA, computational tools for materials science. Calphad 26:273-312. https://doi.org/10.1 016/S0364-5916(02)00037-8

[36] Jaffee RI (1958) The physical metallurgy of titanium alloys. Prog Met Phys 7:65-163. https://doi.org/10.1016/0502-820 5(58)90004-2

[37] Li G, Wang D, Chen Z (2009) Direct reduction of solid $\mathrm{Fe}_{2} \mathrm{O}_{3}$ in molten $\mathrm{CaCl}_{2}$ by potentially green process. J Mater Sci Technol 25:767-771

[38] Panigrahi M, Shibata E, Iizuka A, Nakamura T (2013) Production of $\mathrm{Fe}-\mathrm{Ti}$ alloy from mixed ilmenite and titanium dioxide by direct electrochemical reduction in molten calcium chloride. Electrochim Acta 93:143-151. https://doi.org/ 10.1016/j.electacta.2013.01.089

[39] Panigrahi M, Iizuka A, Shibata E, Nakamura T (2013) Electrolytic reduction of mixed (Fe, Ti) oxide using molten calcium chloride electrolyte. J Alloys Compd 550:545-552. https://doi.org/10.1016/j.jallcom.2012.09.029

[40] Schneider CA, Rasband WS, Eliceiri KW (2012) NIH Image to ImageJ: 25 years of image analysis. Nat Methods 9:671-675. https://doi.org/10.1038/nmeth.2089

[41] Donachie MJ (2000) Understanding the metallurgy of titanium. In: Titanium: a technical guide, 2nd edn. ASM International, Ohio, pp 13-24

[42] Cadoff I, Nielsen JP (1953) Titanium-carbon phase diagram. J Met 5:248

[43] Weston NS, Jackson M (2020) FAST-forge of titanium alloy swarf: a solid-state closed-loop recycling approach for aerospace machining waste. Metals 10:296. https://doi.org/ 10.3390/met10020296

[44] Wei W, Liu Y, Zhou K, Huang B (2003) Effect of Fe addition on sintering behaviour of titanium powder. Powder Metall 46:246-250. https://doi.org/10.1179/003258903225005295

[45] Benson L (2017) Production and development of titanium alloys derived directly from synthetic rutile using electrochemical deoxidation. PhD Thesis, The University of Sheffield

[46] Ivasishin OM, Markovsky PE, Matviychuk YuV, Semiatin SL, Ward CH, Fox S (2008) A comparative study of the mechanical properties of high-strength beta-titanium alloys. J Alloys Compd 457:296-309. https://doi.org/10.1016/j.jallc om.2007.03.070

[47] Mantri SA, Choudhuri D, Behera A, Cotton JD, Kumar N, Banerjee R (2015) Influence of fine-scale alpha precipitation on the mechanical properties of the beta titanium alloy beta21S. Metall Mater Trans A 46:2803-2808. https://doi.org/10. 1007/s11661-015-2944-y

[48] Kilby KT, Jiao S, Fray DJ (2010) Current efficiency studies for graphite and $\mathrm{SnO}_{2}$-based anodes for the electro-deoxidation of metal oxides. Electrochim Acta 55:7126-7133. h ttps://doi.org/10.1016/j.electacta.2010.06.049

Publisher's Note Springer Nature remains neutral with regard to jurisdictional claims in published maps and institutional affiliations. 